\title{
Realization of Strategic Planning in Iran's Higher Education System
}

\author{
Professor Dr. Sorush Niknamian \\ Board Member of Weston A Price Foundation, Washington Dc, USA \\ E-mail: so.niknamian@gmail.com
}

\begin{abstract}
This study investigated the status of strategic planning in Iran higher education system. It was an applied descriptive-survey study. The statistical population consisted of heads and deputies of the universities covered by the Ministry of Science, Research and Technology and the Ministry of Health, Medical Education and Islamic Azad University of Khorasan Razavi ( $N=320) .175$ individuals were selected using cluster random sampling. For data collection, the standard questionnaire of Braison (2010) was used. The reliability coefficient was $(0.910)$ using Cronbach's alpha test. The face and content validity were evaluated using expert opinion and construct validity using confirmatory factor analysis. For statistical analysis of the data, one-variable t-test, skewness and kurtosis test, Friedman test and confirmatory factor analysis were used in Smart Pls, Spss software. The findings indicated that the status of implementation of strategic planning in the studied population was at an unfavorable level, and components of strategic planning are not ranked the same. The component of determining organizational duties had the highest rank among the components of implementation of the strategic planing and the components of initial agreement and strategic issues were ranked next ( $\mathrm{p}$-value <0.05). Given the unfavorable state of implementation of strategic plans, universities and higher education institutions are urged to correctly and timely implement the plans and eliminate existing obstaclesv
\end{abstract}

Key Words: Planning, Strategic Planning, Higher Education System.

\section{Introduction}

The complexity and speed of change in the current global society, which relied more on knowledge, requires community practitioners to implement policies and programs that fit contemporary conditions. Today, organizations operate in a dynamic and complex environment that is constantly changing. Therefore, organizations have to consider these changes in their strategic plans, and higher education is no exception. Therefore, use of strategic planning is considered as a necessity and the higher education system should think and act in a new way. Strategic planning in the higher education system is of particular sensitivity due to its important role in the production and development of the country as the quality of planning in this section can affect the planning of other sections of the country. A large number of organizations are implementing a strategic plan annually, with only $10 \%$ of effectively formulated business strategies being implemented. In other words, $90 \%$ of organizations have strategic planning while their implementation fail and do not achieve its goals. These organizations spend a great deal on developing a strategic plan, and they are aware of the important role that strategic plans can play in achieving their organization goals and, ultimately, the success of organization. Therefore, it is essential that organizations, before implementing a strategically planned program, identify obstacles on the path to reduce the probability of failure.

Today, organizations cannot continue to grow or even survive without planning, due to the ever-increasing changes that occur in their external environments in economic, technological, social, and cultural affairs, and the threats from each side jeopardize their survival. Using different planning methods as a vital and necessary requirement for organizations to overcome environmental challenges around them, such as cultural, political, economic, social and technological change, confrontation with environmental constraints 
and optimal use of available facilities are recommended. One of the most common planning methods in organizations is strategic planning. In strategic planning, strategic decisions are made to achieve the goals set by defining the mission, vision and goals of the organization, with knowledge of the organization and its external environment, and based on that, strategies for achieving the goals are presented. Organizations should understand their current capabilities, analyze their deficiencies, and rely on their abilities to use environmental opportunities and prepare themselves to deal with threats. This is possible in terms of management and strategic planning (dehkordi, 1378). In this regard, the higher education system as a dynamic and objective system plays a critical role in the development process of the country, so that the most important factor of development, namely, human capital, grows in this process and system, and acquires the necessary capabilities and expertise. The rational and appropriate development of this system requires strategic thinking and a good vision. Universities and higher education institutions not only need to train qualified human resources, but also to expand the boundaries of knowledge and conside personal, national, and international growth perspectives. Scientific and research as well as socio-economic goals are one of the issues that increasingly highlight the role of higher education in the country's comprehensive development. According to Parsons, higher education is only outstanding feature of the developing structures of modern societies and is the key to understanding the new world (Salehi, 2004).

Today, universities have become important social organizations playing a major role in national development. Considering high standing of universities and higher education institutions in the production of science, addressing their strategic situation or position can be significant. Despite the significant contribution of universities and higher education institutions to the country's scientific, technological and economic development, this area faces challenges; lack of government funding and facilities, design of an appropriate administrative system for higher education, and provision of knowledge-based society are some of the most important challenges. To overcome these challenges, strategic planning and evaluation has a key role (Asadi et al., 2013).

Studying and recognizing the barriers to implementation and the factors of failure of the strategic plan at the implementation stage and providing solutions for their reduction is an essential element in achieving the goals set and implementing strategies and programs. Now, if these factors are known on why the strategies fail in the implementation phase, we will see the success of more managers and organizations in achieving strategic goals, which will underscore the need for the growth and advancement of organizations in the competitive and turbulent environment today. And, it is of particular importance and prevents the loss of large amounts of money in the field of strategic management (Khalili Shourinini and Ghazari, 1393).

The process of strategic management in educational institutions is aimed at identifying the factors influencing their change and opening up, which in fact, selective solutions will in some way reflect policies of the institution. In universities, the factors influencing change that affect strategic planning include engaged sectors, tasks and activities of people, communication, organization's status, methods and norms for the desired change (Huntsman, 1994, 27).

Strategic planning is one of the basic necessities in universities which is a systematic effort to implement main strategies and apply them to achieve goals. This planning identifies goals of the organization according to its mission and strengths and weaknesses through environmental studies, opportunities and threats. In this way, it sets and realizes more realistic goals. The main goal of the strategy is to connect the future of the university to the predicted changes in the environment, analyze the underlying risk factors of the environment and provide solutions that are more likely to achieve the goal.

Use of strategic planning by university administrators can bring positive benefits in the long run. Strategic planning reinforces strategic vision of the organization, not making members limited to the boundaries of 
the present, focusing on distant horizons, and creating a common vision among them, which include the following: assignment of mission, targeting or separation of mission to quantitative and qualitative shortterm goals; defining policies and strategies; and tactical planning (Rahman Sarsht, 2005).

Strategic planning is to determine the organization's goals and make decisions about comprehensive operational plans that achieve the long-term and critical goals of the organization in a competitive environment, which also defines the goals and general lines of the long-term activities and missions of the organization (Armstrong, 2005). Strategic planning requires a stable environment, environmental factors in balance with continuous change, actionable and predictable response (Gordon et al., 2000, 850-841 )

Strategic planning is a kind of real-world modeling that formulates strategy by processing information about important internal and external factors (Saibi, 40: 1373).

Strategic planning is a long-term plan for effective management of opportunities and environmental threats, and examining the strengths and weaknesses of the organization. The development of a strategic plan involves defining missions, identifying educational goals, designing strategies, and setting policy guidelines (Hanger \& Wien, 2007, p. 22).

\section{Strategic Planning at Universities and Higher Education Centers}

Universities and higher education institutions are organizations that simultaneously produce diverse products

Their products are development of scientific abilities, knowledge of individuals, organizations and groups of society and expansion of knowledge boundaries through education and research, and, most of the economies in the present age are based on the knowledge and intellectual activity produced at universities. Strategic planning has been presented in universities and higher education institutions in recent years, and most countries have taken advantage of it in their higher education institutions for effective management. Universities and other higher education institutions turned to strategic planning with a 20 -year delay from profit organizations and from the 1980s to the early 1990s.

Peterson considers four main elements of strategic planning at universities as follows:

An assessment of the environment to identify trends or possible changes in the environment and its implications for the university

University evaluation to identify the strengths and weaknesses of its problems and capabilities

Valuation assessment (studying the values and ideas of interest groups and responsibilities of the university toward these groups and society)

Compiling comprehensive plans for shaping the pattern, design, or direction of the university based on the findings of the first three elements (Dooris, 2003).

Today, universities are trying to find a competitive advantage using their strategy tools to identify their position in their external environment and address new challenges. Strategic Planning in Higher Education is the formal process of helping universities to identify and maintain optimal coordination with the most 
important environmental factors, including political, social, economic, technological and educational ecosystems inside or outside the university (Rowley et al., 1997).

In this way, it seems that universities are turning to strategic planning in order to overcome the constraints surrounding the environment and use its opportunities. In universities, for strategic planning, after identifying strategies at the higher level (university and its various units), task-level strategies are aligned with them, in order to eventually realize the vision, mission and goals of the university.

The purpose of this study was to determine the status of realization of strategic planning in universities and centers of excellence and to remove barriers to it. It is a positive step for the correct and timely implementation of strategic plans.

\section{The Strategic Planning Process in the Braison Model}

Initial agreement: The strategic planning needs of the planning organization are examined and familiarity with this type of planning are taken.

Determining the tasks: The organization formal and informal duties are the "must-do" that the organization faces. At this stage, the goal is for the organization and its members to identify with tasks assigned by competent authorities (government, parliament, etc.).

Stakeholder analysis: The individual stakeholder is a group or organization that can influence the organization's attitudes, resources or outputs Stakeholder analysis is a valuable advance for organizing the mission of organization.

Setting the mission statement of the organization: it is the philosophy of existence or the role that a set (company, organization ...) take in society to provide the service with its survival. in the other words, it can be said that the mission is a general statement of the firm's intentions

Understanding the organization's environment: Understanding the organization's environment is to examine the environmental characteristics of the organization. This review includes the analysis of strengths, opportunities and weaknesses, economic, social and cultural conditions, lifestyle, technological development, human resource situation, labor market situation and supply and demand of manpower.

Determining strategic issues facing the organization: Strategic issues are key political decisions that affect the authority, mission, values, product or service provided, customers or users, costs, financing, organization, or management. The goal of this stage is to identify the choices that the organization faces.

Defining Strategies: It is the master plan of the organization that shows how the organization achieves its missions and goals. The strategy will maximize competitive advantage and minimize competitive deficiencies.

Explanation of plans and actions: Plans and actions are the framework for delegating authority for decision making to middle managers in order to facilitate future decision makers. These frameworks, which are in some ways restrictive and in some ways guiding the administrators of the field, are described as plans and actions. 
Setting the Organizational Outlook for the Future: An Organizational Perspective is a description of the future of the organization or company, in other words, an image of the status of the company when its goals and strategies are achieved.

Annual Action Plan: The one-year operational program is the details and methods required to achieve goals and strategies. This type of program is aimed at directing and controlling individual activities and resource consumption and determining short-term and executive actions and plans.

\section{Conceptual model of research}

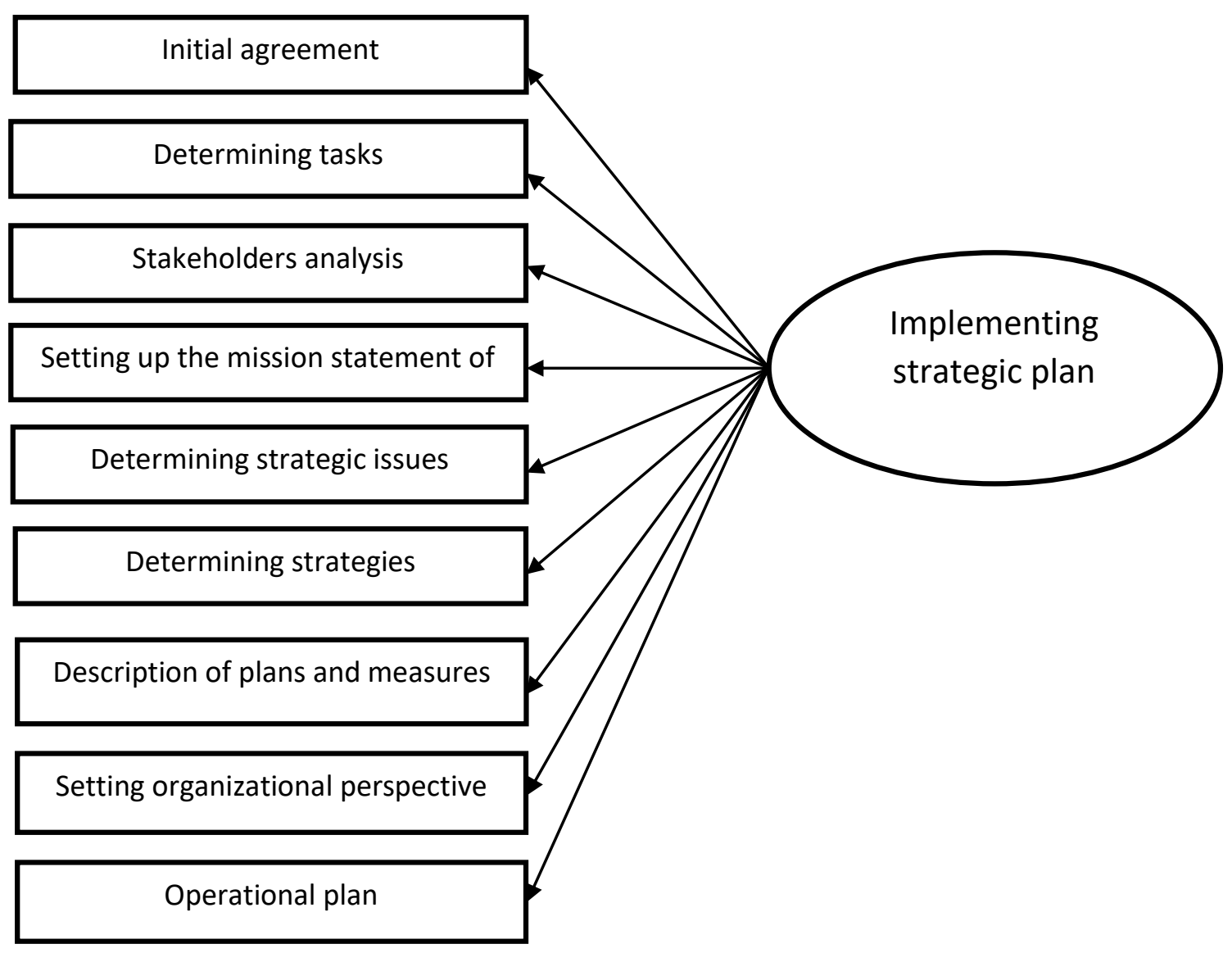

Figure 1. Implementing strategic planning in Iran higher education system

\section{Methodology}

The statistical population of the study consisted of heads and deputies of the universities under the Ministry of Science, Research and Technology, Ministry of Health, Medical Education and Islamic Azad University of Khorasan Razavi ( $\mathrm{N}=320)$. The sample size was 175 women based on the Krejci and Morgan tables using multistage sampling method and cluster random sampling method.

In this research, strategic planning variable is measured through the standard questionnaire of Braison (2010). The questionnaire has a Likert scale assessing realization of strategic plans. 
In this research, the strategic planning variable is measured through a 32-item questionnaire. Table 1-1 defines how the questions are answered by its components.

The Strategic Planning Questionnaire is based on the Braison Model (2010). The questionnaire includes components of initial agreement, task determination, stakeholder analysis, organization mission statement, organization knowledge of the environment, strategic planning issues, organization planning, strategies identification, description of plans and measures, setting organizational perspective for the future and the one-year operational plan. The questionnaire has 32 items(the initial agreement (1 to 4), organizational tasks (5 to 7), stakeholder analysis (8-10), mission (11 to 13), knowledge of organizational environment (14-16), defining strategic issues (17-21), determining strategies (22-24), describing plans and measures (25-26), assessing organization perspective (28-30) and operational plan (31 to 32).

\section{Normal Distribution of Research Variables}

One of the important assumptions for examining the research questions and hypotheses in the statistical tests is the study of normal distribution of data. If the data have a normal distribution, parametric tests can be used to test the assumptions. Nonparametric tests are used if data are not normal. One of the ways of studying the distribution of data is using the coefficients of skewness and kurtosis. Under this assumption, data are normal, with a critical proportion at interval (-2.85 and 2.85) (Klein, 2011)

As can be seen, all the coefficients obtained are in the distance (-2.85 and 2.85); therefore, this assumption exists for all strategic planning variables; therefore, parametric statistical tests can be used to study the research questions.

Table 1. Skewness and kurtosis coefficients of research variables

\begin{tabular}{|l|c|c|c|c|}
\hline Variable & Skewness & Critical value & Skewness & Critical value \\
\hline Initial agreement & $0 / 258$ & $1 / 402$ & $-0 / 799$ & $-2 / 189$ \\
\hline $\begin{array}{l}\text { Determining } \\
\text { organizational } \\
\text { tasks }\end{array}$ & $-0 / 316$ & $-1 / 717$ & $-0 / 173$ & $-0 / 474$ \\
\hline $\begin{array}{l}\text { Stakeholder } \\
\text { analysis }\end{array}$ & $0 / 050$ & $0 / 272$ & $-0 / 334$ & $-0 / 915$ \\
\hline Mission & $0 / 346$ & $1 / 880$ & $-0 / 576$ & $-1 / 578$ \\
\hline $\begin{array}{l}\text { Understanding } \\
\text { organizational } \\
\text { environment }\end{array}$ & $0 / 241$ & $1 / 310$ & $-0 / 258$ & $-0 / 707$ \\
\hline Strategic issues & $0 / 451$ & $2 / 451$ & $0 / 488$ & $1 / 337$ \\
\hline $\begin{array}{l}\text { Determine } \\
\text { strategy }\end{array}$ & $0 / 420$ & $2 / 283$ & $-0 / 282$ & $-0 / 773$ \\
\hline $\begin{array}{l}\text { Describe designs } \\
\text { and measures }\end{array}$ & $0 / 371$ & $2 / 016$ & $-0 / 130$ & $-0 / 356$ \\
\hline $\begin{array}{l}\text { Organization } \\
\text { perspective }\end{array}$ & $0 / 505$ & $2 / 745$ & $0 / 137$ & $0 / 375$ \\
\hline $\begin{array}{l}\text { Operational } \\
\text { Program }\end{array}$ & $0 / 376$ & $2 / 043$ & $-0 / 519$ & $-1 / 422$ \\
\hline $\begin{array}{l}\text { implementing } \\
\text { strategic plan }\end{array}$ & $0 / 422$ & $2 / 293$ & $-0 / 351$ & $-0 / 962$ \\
\hline
\end{tabular}


Reliability: Cronbach's alpha and composite reliability (CR) were used to measure reliability of questionnaires, the results of which are presented in Table 3. The acceptable value for the Cronbach's alpha coefficients and the combined reliability is at least equal to 0.6 (Hair et al., 2009).

Table 2. Reliability of instruments (questionnaires)

\begin{tabular}{|l|c|c|}
\hline Variable & Cronbach coefficient & CR \\
\hline Initial agreement & $0 / 732$ & $0 / 932$ \\
\hline $\begin{array}{l}\text { Determining organizational } \\
\text { tasks }\end{array}$ & $0 / 606$ & $0 / 792$ \\
\hline Stakeholder analysis & $0 / 723$ & $0 / 844$ \\
\hline Mission & $0 / 594$ & $0 / 699$ \\
\hline $\begin{array}{l}\text { Understanding organizational } \\
\text { environment }\end{array}$ & $0 / 695$ & $0 / 827$ \\
\hline Strategic issues & $0 / 625$ & $0 / 771$ \\
\hline Determine strategy & $0 / 657$ & $0 / 914$ \\
\hline Describe designs and measures & $0 / 51$ & $0 / 803$ \\
\hline Organization perspective & $0 / 713$ & $0 / 823$ \\
\hline Operational Program & $0 / 531$ & $0 / 807$ \\
\hline implementing strategic plan & $0 / 732$ & $0 / 920$ \\
\hline Accepted value & $>0 / 6$ & $>0 / 6$ \\
\hline
\end{tabular}

The validity is evaluated by the factor loads, which is a load of over 0.4 , so that it can be considered valid and an item that measures our index. Otherwise, it is necessary to identify inappropriate items and dimensions and to improve the model by eliminating those items that have caused them to reduce the load factor. The factor load results of each research questionnaire are presented below

Table 3. Standard factor load and t values for implementation of the strategic plan

\begin{tabular}{|c|c|c|c|}
\hline item & $\begin{array}{l}\text { Standardized } \\
\text { factor loading }\end{array}$ & t-value & p-value \\
\hline 1 Item & $0 / 783$ & $29 / 319$ & $<0 / 05$ \\
\hline 2 Item & $0 / 741$ & $19 / 501$ & $<0 / 05$ \\
\hline 3 Item & $0 / 732$ & $20 / 651$ & $<0 / 05$ \\
\hline 4 Item & $0 / 718$ & $23 / 986$ & $<0 / 05$ \\
\hline 5 Item & $0 / 724$ & $15 / 742$ & $<0 / 05$ \\
\hline 6 Item & $0 / 772$ & $17 / 968$ & $<0 / 05$ \\
\hline 7 Item & $0 / 747$ & $19 / 506$ & $<0 / 05$ \\
\hline 8 Item & $0 / 802$ & $26 / 268$ & $<0 / 05$ \\
\hline 9 Item & $0 / 837$ & $39 / 405$ & $<0 / 05$ \\
\hline 10 Item & $0 / 767$ & $19 / 90$ & $<0 / 05$ \\
\hline 11 Item & $0 / 838$ & $22 / 618$ & $<0 / 05$ \\
\hline 12 Item & $0 / 612$ & $8 / 026$ & $<0 / 05$ \\
\hline 13 Item & $0 / 515$ & $4 / 954$ & $<0 / 05$ \\
\hline 14 Item & $0 / 828$ & $23 / 834$ & $<0 / 05$ \\
\hline 15 Item & $0 / 712$ & $9 / 618$ & $<0 / 05$ \\
\hline 16 Item & $0 / 811$ & $20 / 413$ & $<0 / 05$ \\
\hline 17 Item & $0 / 181$ & $1 / 699$ & $<0 / 05$ \\
\hline 18 Item & $0 / 745$ & $20 / 318$ & $<0 / 05$ \\
\hline 19 Item & $0 / 755$ & $17 / 877$ & $<0 / 05$ \\
\hline
\end{tabular}




\begin{tabular}{|c|c|c|c|}
\hline 20 Item & $0 / 661$ & $13 / 662$ & $<0 / 05$ \\
\hline 21 Item & $0 / 752$ & $25 / 033$ & $<0 / 05$ \\
\hline 22 Item & $0 / 84$ & $26 / 355$ & $<0 / 05$ \\
\hline 23 Item & $0 / 739$ & $17 / 567$ & $<0 / 05$ \\
\hline 24 Item & $0 / 756$ & $20 / 900$ & $<0 / 05$ \\
\hline 25 Item & $0 / 799$ & $28 / 176$ & $<0 / 05$ \\
\hline 26 Item & $0 / 840$ & $33 / 576$ & $<0 / 05$ \\
\hline 27 Item & $0 / 748$ & $19 / 381$ & $<0 / 05$ \\
\hline 28 Item & $0 / 782$ & $24 / 749$ & $<0 / 05$ \\
\hline 29 Item & $0 / 752$ & $19 / 972$ & $<0 / 05$ \\
\hline 30 Item & $0 / 647$ & $12 / 477$ & $<0 / 05$ \\
\hline 31 Item & $0 / 877$ & $44 / 610$ & $<0 / 05$ \\
\hline 32 Item & $0 / 766$ & $16 / 790$ & $<0 / 05$ \\
\hline
\end{tabular}

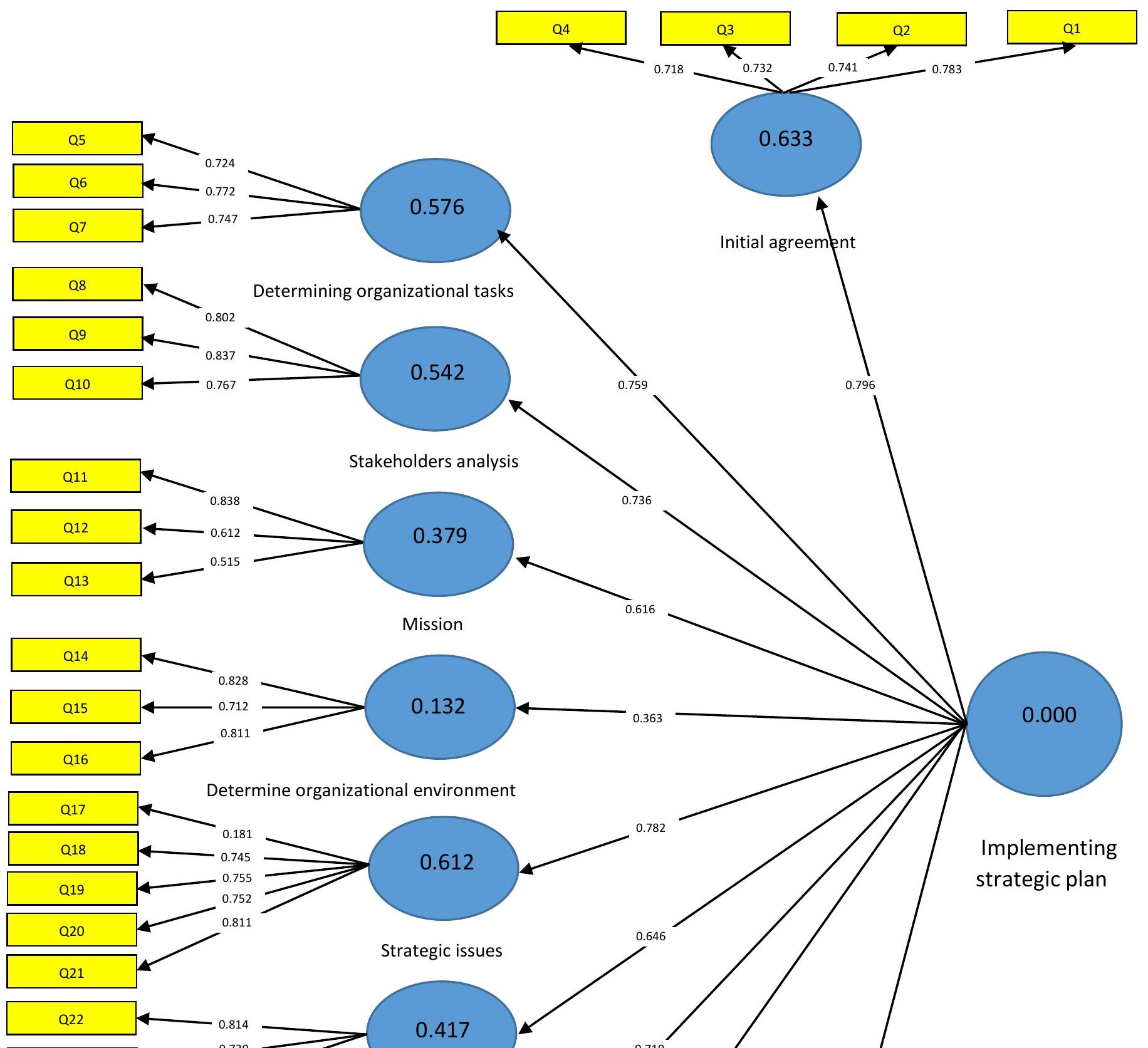


Figure 2. Results of confirmatory factor analysis of implementation of the strategic plan (standardized load factor)

In Table 2, for the strategic plan implementation, item 17 has factor loadings of less than 0.3; they are excluded from the analysis process. In order to examine convergent validity of instruments, the average variance extracted (AVE) has been used. The results are shown in Table 5. The acceptable value for the AVE is at least 0.4 (Neonaly \& Brestin, 1994).

Table 5. Convergence of measuring instruments (questionnaires)

\begin{tabular}{|l|c|}
\hline Variable & AVE \\
\hline Initial agreement & $0 / 553$ \\
\hline Determining organizational tasks & $0 / 559$ \\
\hline Stakeholder analysis & $0 / 643$ \\
\hline Mission & $0 / 447$ \\
\hline Understanding organizational environment & $0 / 616$ \\
\hline Strategic issues & $0 / 432$ \\
\hline Determine strategy & $0 / 593$ \\
\hline Describe designs and measures & $0 / 672$ \\
\hline Organization perspective & $0 / 539$ \\
\hline Operational Program & $0 / 677$ \\
\hline implementing strategic plan & $0 / 475$ \\
\hline Accepted value & $0 / 4$ \\
\hline
\end{tabular}

Status of implementation of strategic plan in the studied population

H0: Organizational innovation in the population is not optimal $(3 \geq \mu)$. 
H1: Organizational innovation is in the favorable level $(3<\mu)$.

As shown in Table 6, given that the p value of the test (1.000) is more than the significant level (0.05), the zero assumption cannot be ruled out, and it can be argued that in the studied population the implementation is not optimal. In other words, according to the mean obtained for this variable, it can be argued that the implementation of strategic planning in the population is at an unfavorable level (below the mean).

Table 6. Status of strategic planning in the population

\begin{tabular}{cccc}
\hline $\begin{array}{c}3 / 00=\text { Theoretical variable } \\
\text { value }-\mathrm{p}\end{array}$ & $\mathrm{t}$ Statistics & $\mathrm{SD}$ & P-value \\
\hline $1 / 000$ & $-7 / 22$ & $0 / 64$ & $2 / 65$ \\
\hline
\end{tabular}

Study of organizational innovation components in the population

H0: The strategic planning components in the studied population are not at favorable conditions $(3 \geq \mu)$.

H1: The strategic planning components in the studied population are in a favorable situation $(3<\mu)$.

According to the results of Table 4-19, it can be argued that in the studied population, all the components of implementing strategic plan are at an unfavorable level (p-value <0.05). In other words, based on the mean of these components, it can be argued that components of the initial agreement, determining organizational tasks, stakeholder analysis, mission, recognition of organizational environment, strategic issues, strategy determination, description of the plans and measures, organization's vision and operational program are in undesirable levels (below the average).

Table 7. Status of components of strategic planning implementation in the studied population

\begin{tabular}{|c|c|c|c|c|}
\hline $\begin{array}{l}3 / 00=1 \\
\text { value-p }\end{array}$ & $\begin{array}{l}\text { retical mean } \\
\text { t statistics }\end{array}$ & SD & M & Variable \\
\hline $1 / 000$ & $-4 / 31$ & $0 / 80$ & $2 / 74$ & Initial agreement \\
\hline $0 / 983$ & $-2 / 14$ & $1 / 15$ & $2 / 81$ & Determining organizational tasks \\
\hline $1 / 000$ & $-3 / 63$ & $1 / 24$ & $2 / 66$ & Stakeholder analysis \\
\hline $1 / 000$ & $-4 / 52$ & $1 / 12$ & $2 / 62$ & Mission \\
\hline $0 / 981$ & $-2 / 10$ & $1 / 41$ & $2 / 78$ & Understanding organizational environment \\
\hline $1 / 000$ & $-6 / 88$ & $0 / 67$ & $2 / 65$ & Strategic issues \\
\hline $1 / 000$ & $-5 / 07$ & $0 / 83$ & $2 / 68$ & Determine strategy \\
\hline
\end{tabular}




\begin{tabular}{lllll}
\hline $1 / 000$ & $-7 / 89$ & $0 / 84$ & $2 / 50$ & Describe designs and measures \\
\hline $1 / 000$ & $-9 / 30$ & $0 / 76$ & $2 / 46$ & Organization perspective \\
\hline $1 / 000$ & $-7 / 23$ & $0 / 88$ & $2 / 52$ & Operational Program \\
\hline
\end{tabular}

Ranking components of the implementation of strategic plan in the studied population The results of Table 4-35 show that the components of implementation of strategic plan are not ranked the same and the component of determining organizational tasks has the highest rank among others, and the initial agreement and strategic issues components are ranked next (P-value 05/0).

Table 1. Ranking Components of the Strategic Plan Implementation

\begin{tabular}{|l|c|c|c|c|}
\hline Variable & Rank & Mean rank & Chi-square & Value-p \\
\hline Initial agreement & 2 & $6 / 00$ & & \\
\hline $\begin{array}{l}\text { Determining } \\
\text { organizational } \\
\text { tasks }\end{array}$ & 1 & $6 / 07$ & $33 / 616$ & \\
\hline $\begin{array}{l}\text { Stakeholder } \\
\text { analysis }\end{array}$ & 7 & $5 / 41$ & & \\
\hline Mission & 6 & $5 / 50$ & & \\
\hline $\begin{array}{l}\text { Understanding } \\
\text { organizational } \\
\text { environment }\end{array}$ & 5 & $5 / 65$ & & \\
\hline Strategic issues & 3 & $5 / 76$ & & \\
\hline $\begin{array}{l}\text { Determine } \\
\text { strategy }\end{array}$ & 8 & $5 / 69$ & & \\
\hline $\begin{array}{l}\text { Describe designs } \\
\text { and measures }\end{array}$ & 10 & $5 / 05$ & & \\
\hline $\begin{array}{l}\text { Organization } \\
\text { perspective }\end{array}$ & 9 & $5 / 85$ & & \\
\hline $\begin{array}{l}\text { Operational } \\
\text { Program }\end{array}$ & 4 & & & \\
\hline
\end{tabular}




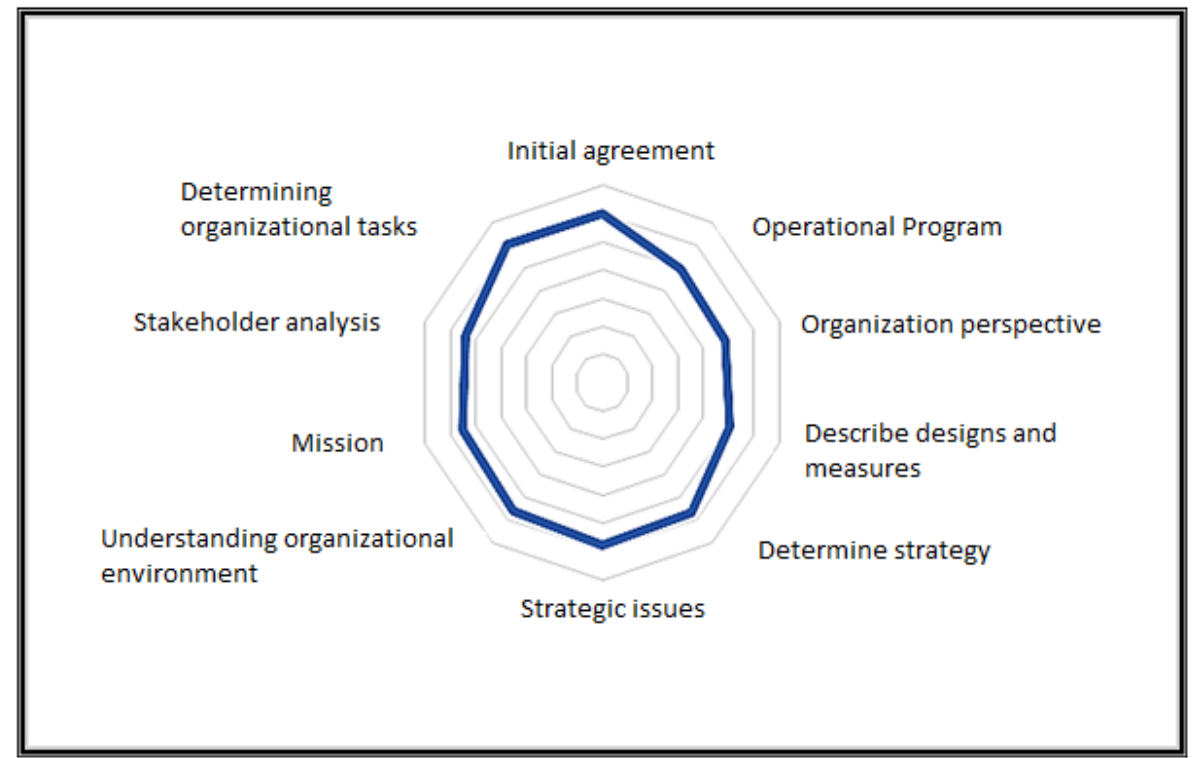

\section{Discussion and conclusion}

Perhaps we can claim that senior executives in Iran organizations are engaging in day-to-day activities and resolve current problems more than necessary, and thus, they stay away not only from their main task, which is planning for the future of the organization, but also their strategic vision. This lack of strategic thinking has become a major disadvantage in the organization. Organizations need strategic executives to strategically carry out a strategic plan. Studies (Kaplan \& Norton, 1996) reflect the fact that only $15 \%$ of the senior management team spend at least one hour per month devoting themselves to strategy negotiations.

(Maxwell et al., 1997) also concluded that the successful implementation of strategic plans of an organization depends on the explicit commitment of senior executives to those strategies. Lack of a belief in the usefulness of a strategic plan is a barrier in the realm of strategic planning that is referred to by most executives. Perhaps, negotiation and dialogue is one of the paths that will change the attitude and ultimately align the view of managers to this category and lead to a belief in the usefulness of the strategic program. The need to hold these meetings prior to the compilation, at the time of the compilation, and in the implementation of the strategic program, has been emphasized by the field administrators, in order to provide the conditions for their association with the organization. Since implementation of a strategic plan means a major change in the organization, these changes require that human resources accept them, and training and motivation is a prerequisite for accepting these changes. The organization's human resource planning should also be in such a way as to target the organization (Turkman Asadi, 1393).

Factors such as inadequate human resources, inadequate resources allocation, financial constraints, unpredictable factors and environmental variables, inadequate use of advisers and experts in outsourcing strategies, changes made according to individual viewpoints and individual managers' predictions. In this regard, Goudarzi (1394), Herbinak (2006), Khalili Shurin (1393), Rahimnia (1391), Haghighi (2011), Barson (2010), Burns (2008) described the above as important environmental barriers to strategic planning. 
Structural mismatch with strategies, poor participation of task forces on strategy implementation, mechanistic nature of organizational structure, lack of awareness of corporate employees of strategy, weak organizational culture, weakness in processes and operations of organization, are important factors of organizational obstacles in implementing strategic planning. The inconsistency of organizational structure with the developed strategies is an obstacle to the implementation of strategic plans. In this regard, Heide, Gronhag and Johansen (2002) in their study showed the factors related to the structure of Money as an important obstacle in the way of implementation of the strategy. They also argued that insistence of managers on maintaining existing structures would lead to disparities between strategy and organizational structure.

Another reason why universities and institutes of higher education are weak in implementing strategic plans is that due to the lack of specialists in the strategic plan and their lack of effective role in the strategy development process, the role of individuals and external experts in planning are more intense and due to the lack of knowledge and insight of the external experts of the strengths and weaknesses, the planning process was not carried out in principle, and this causes negligting many issues including stakeholders needs, rivals positions, etc. The evidence is the fact that most strategic programs have been implemented by academics in a variety of ways, and the organization has not cooperated in compiling them.

In this regard, Hayd et al. (2002) stated that compared to $40 \%$ of unsuccessful organizations, 59\% of successful organizations considered partnerships with foreign sponsors or consultants as a facilitating process for success. The lack of alignment of organizational and individual goals, which an incentive necessitates such an alignment, as well as, the allocation of human resources as other obstacles to the implementation of the strategic plan. If human resource dimension is not considered, even the best system for strategic management is condemned to failure. Therefore, when choosing any strategy, individuals need to adapt their talent and abilities to the task of implementing the strategy (David, 2005). The results of statistical tests done on realization of strategic plans in universities and higher education establishments confirmed that it is not satisfactory. These results are in line with Khalili (1393), Rahimnia (2009), Haghighi (2011) Akomus (2001), Miller (1997), Kaplan and Norton (1996), Kratland (2008).

The strategies that the researcher proposes to better implement strategic plans in the higher education system are:

1. Achieving consensus on the strategic planning process

2. Transparency of the mission and values of the organization

3. Assessing the external environment and internal status of the organization to determine the strengths and weaknesses of the organization and the opportunities and environmental threats.

A review of the set of forces and environmental trends, including political, economic, social, educational and technological trends, can help key planners and decision makers to identify opportunities and challenges ahead.

In general, it is recommended to do the following three steps:

- Monitor the environment to determine the underlying and influential trends

- Analyze these trends to identify and determine their importance

- Collecting reports to facilitate planning and decision making 
The organization must focus on successful strategies and ask itself whether these strategies will continue, change or end. Unsuccessful strategies should either be replaced or abandoned by other strategies.

4. Create a friendly, tolerant, reliable and scientific environment

5. Providing attractive, efficient, cost effective, efficient and effective physical facilities

6. Smoothing and simplifying the traditional hierarchical structure

7. Establishing a system of collaboration among all university staff and stakeholders to determine the direction and review of progress and to balance the priorities.

8. Facilitating communication, understanding and consensus on major decisions

9. Strengthening achievement of goals within the framework of values and mission of universities

\section{Refrences}

Armstrong, Michael. (2005). Strategic Management of Human Resources. Arabi, Seyyed Mohammad; Izadi, Davoud, Publications Office of Cultural Studies, Second Edition.

Asadi, Fatemeh, Taban, Mohammad, Safari Kareh, Mohammad. (2013). Analysis of Strategic Situation of Universities and Nonprofit Higher Education Institutions in Iran: Using a Comprehensive Strategic Analysis Approach. Journal of Business Management, Volume 5, Issue 3.

Brison, Johm. M. (1993). Strategic Planning, Abbas Monavarian, Publications of the Institute for Management and Planning of Education and Research, Fourth Edition, 2007.

Turkman Asadi, Sajjad (2014). Identifying Barriers to Strategic Planning in Government Organizations, Master's Thesis in Ferdowsi University of Mashhad.

Haghi, Mohammad, Rahmani Yushanloie, Hussein, Rezaani, Tohid, Torabi, Asghar. (2011). Prioritization of Barriers to Implementing Strategic Organizational Strategies. Strategic Management Researches, No. 49, Winter 2011.

Khalili Shourin, Sohrab, Madzari, Mehdi. (2014). Understanding the barriers to implementing strategic plans and prioritizing them. Quarterly Journal of Strategic Management Research, Vol. 20, No. 56, Winter 2014.

Dehkordi, Forouzandeh (1999). A Review of Strategic Planning Models. Management Knowledge. Twelfth Year. 45th Century. 1999

David F. (1384). Strategic Management, translation by Ali Parsayian and Mohammad Arabi, Publications Office of Cultural Research, Tehran, Seventh Edition.

Rahman Sarsat, Hossein. (2005). Management Strategies, Publishing Co. of Idehozaran Fan and Art, First Printing. 2005.

Rahimnia, Fariborz; Gharebaghi; Nastaran; Bahpour, Inspirational. (2012). A Conceptual Model To Obtain Organizational Barriers To Implementing Strategy And Organizational Health In The Background Of Organizational Culture. The 4th Urban Planning and Management Conference 20 and 21 April 2012. 
Saibi M. (1994). Strategic Management, Strategy Process. Publications Public Administration Center, Tehran, First Edition.

Salehi, Zaker. (2005). Iranian University, An Introduction to Sociology of Higher Education, Kavir Publishing, Tehran.

Goodarzi, Mahmoud Ghorbani, Mohammad Hossein Safari, Hamid Reza (2015) Identification and formulation of barriers to implementation of strategic plans. Sports Management Studies, No. 13,. Shahrivar 94

Mirza'i, David (2005). A Look at the Strategic Planning of the Social Security Organization. Strategic planning in the context of the challenges ahead, Atieh Weekly, 542, 54-40.

Hanger, Jay, David; Willen, El, Thomas. Basics of Strategic Management. Translated by Seyyed Mohammad Arabi and Davoud Izadi (2005). Tehran. Cultural Research Publishers 